\title{
Landform and local site effects on the colonies worst-hit by the 2004 mid-Niigata prefecture, Japan, earthquake
}

\author{
Masayuki Yoshimi ${ }^{1}$, Taku Komatsubara ${ }^{2}$, Yoshinori Miyachi ${ }^{2}$, Katsumi Kimura $^{2}$, Haruko Sekiguchi ${ }^{1}$, \\ Masayuki Saeki ${ }^{3}$, Sunao Kunimatsu ${ }^{1}$, Kunikazu Yoshida ${ }^{1}$, Masanori Ozaki², Tsutomu Nakazawa ${ }^{2}$, \\ Rei Nakashima ${ }^{2}$, and Hidetaka Saomoto ${ }^{1}$ \\ ${ }^{1}$ Active Fault Research Center, GSJ, National Institute of Advanced Industrial Science and Technology, Tsukuba, Ibaraki 305-8567, Japan \\ ${ }^{2}$ Institute of Geology and Geoinformation, GSJ, National Institute of Advanced Industrial Science and Technology, Tsukuba, \\ Ibaraki 305-8567, Japan \\ ${ }^{3}$ Department of Civil Engineering, Faculty of Science and Technology, Tokyo University of Science, Noda, Chiba 278-8510, Japan
}

(Received February 24, 2005; Revised June 24, 2005; Accepted June 28, 2005)

\begin{abstract}
Landform and damage classification surveys have been conducted on six colonies worst-hit by the 2004 midNiigata prefecture earthquake. The landform was classified using aerial photographs taken by the US Air Force in 1947. Damage degree of each structure has been classified into four classes including foundation damage class, and location of each structure has been mapped with damage class. Around 1,000 houses and stores have been classified and mapped. In five of six colonies, buildings on the fans composed of colluvial deposits have been more likely suffered severe damage than those on terraces or dissected valleys. In the other colony located on a flood plain, no clear difference in degree of damage among landforms has been observed.
\end{abstract}

Key words: 2004 mid-Niigata prefecture earthquake, damage distribution, terrace, fan, local site effect.

\section{Introduction}

The October 23, 2004, mid-Niigata prefecture earthquake $(\mathrm{Mw}=6.6)$ was the most suffering earthquake in Japan since the 1995 Kobe earthquake. Forty-six people were killed (thirty of them were results of shock, postearthquake fatigue or accident on a post-earthquake work), over 600 were heavily injured, almost 3,000 residential houses were completely collapsed, and numerous landslides destroyed entire upland in the focal area (Niigata Prefecture, 2005).

Soon after the shock, from October 28th until November 3 rd, we conducted a quick field survey on damage distribution of buildings, mainly wooden houses or barns, in the focal area. We found that most of heavily damaged colonies were located in an area within $10 \mathrm{~km}$ from the epicenter of the main shock (Fig. 1). Among those heavily damaged colonies, we recognized six worst-hit colonies (MuikaichiNakagata, Budokubo, Kawaguchi, Tamugiyama, Wanazu and Shindojima), where more than $20 \%$ of houses had been totally collapsed by shaking. Though the area of each worst-hit colony was no more than $1 \mathrm{~km}^{2}$, clear contrast in severity of damage among subregions was observed. These indicated that there could have been local amplification in those heavily damaged or worst-hit colonies.

Strong ground motions for the main shock have been recorded in the focal area. Peak ground velocities (PGVs) are shown in Fig. 1. As a whole, these PGVs agree well with general feature of the damage distribution: no heav-

Copy right(c) The Society of Geomagnetism and Earth, Planetary and Space Sciences (SGEPSS); The Seismological Society of Japan; The Volcanological Society of Japan; The Geodetic Society of Japan; The Japanese Society for Planetary Sciences; TERRAPUB ily damaged colonies are found in an area with PGV less than $50 \mathrm{~cm} / \mathrm{s}$, and the largest and the second largest PGV, $152 \mathrm{~cm} / \mathrm{s}$ and $147 \mathrm{~cm} / \mathrm{s}$, is found at one of the worst-hit colonies, Wanazu and Kawaguchi, respectively. However, even around an area with PGV more than $100 \mathrm{~cm} / \mathrm{s}$, we did still observed slightly or moderately damaged colonies.

This paper is intended to report results of our detailed investigation on those worst-hit colonies. The main objective of our work is to figure out relations between damage degree and landform. Our investigation is made up of landform classification and classification of damage of almost all houses or barns on those colonies.

\section{Investigation on Worst-hit Colonies \\ 2.1 Damage investigation}

Following the quick survey stated above, we carried out a series of field investigations for damage distribution in the worst-hit colonies from Nov. 12 to Nov. 13, 2004. We observed several types of wooden buildings, mainly two-story ones; a non-engineered wood-frame traditional Japanese building, an engineered wood-frame building, an engineered wood-frame and panel building, and an engineered wooden building with reinforced concrete foundation designed for heavy snowfall. Performances to earthquake differ among structure types. The non-engineered wood frame building is the most vulnerable to ground shaking. Ground motion for Japanese seismic intensity scale of 7 expects to collapse more than 30 percent of buildings of this type.

Severity of damage of a house or a barn has been classified into three classes by its outward appearance; total collapse (D3), partial destruction (D2), minor or minimal 


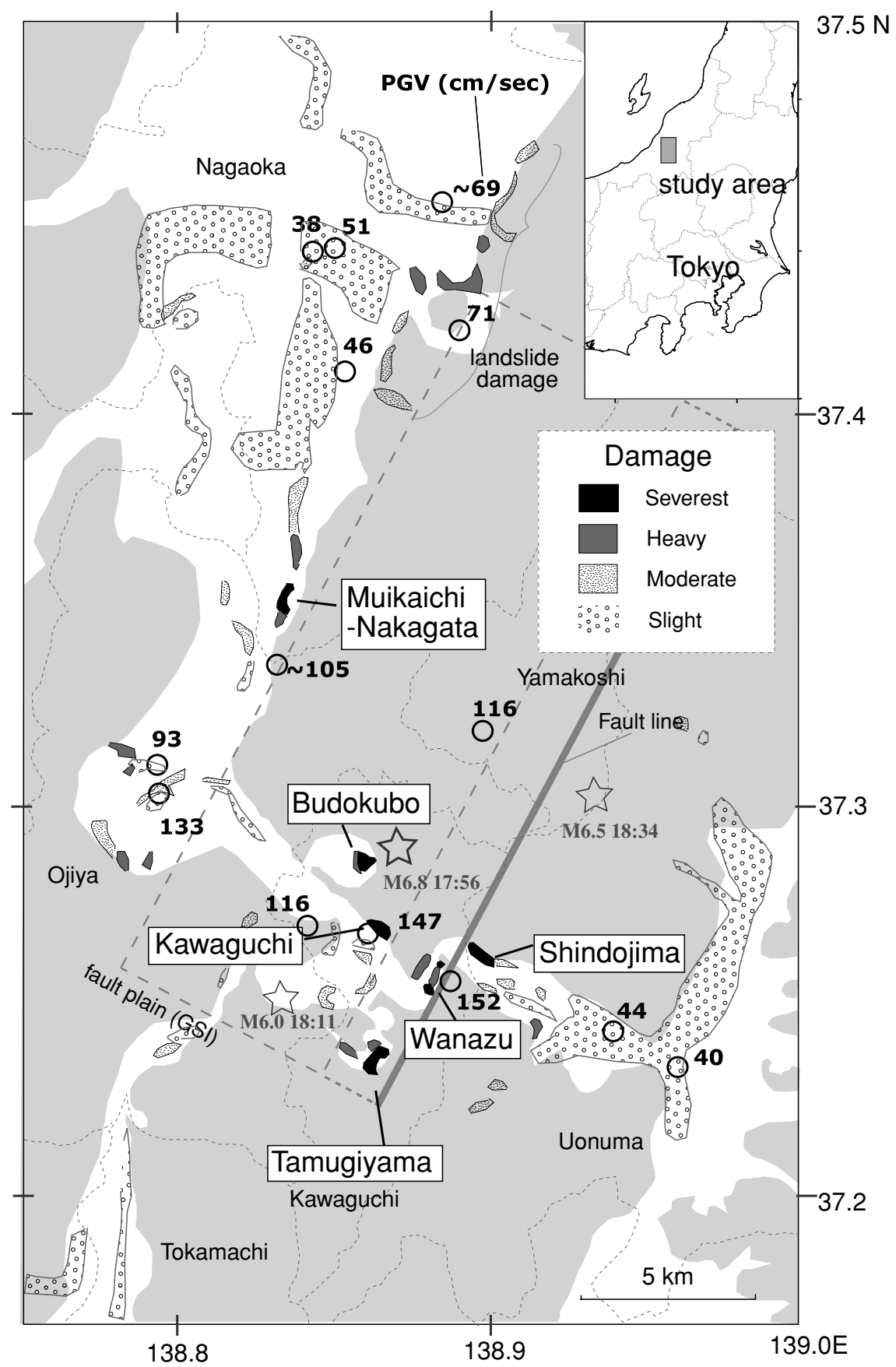

Fig. 1. Damage distribution in the focal area of the mid-Niigata prefecture earthquake obtained by our quick survey. Worst-hit colonies are shown as patches in black color. Stars represent the epicenters of the main shock and major aftershocks (Japan Meteorological Agency, 2004). Tilted rectangle with broken lines shows surface projection of the seismic fault plain deduced from leveling data (Geographical Survey Institute Japan, 2004). Each number with a blank circle is peak ground velocity at a location denoted with the circle recorded by JMA, National Institute for Land and Infrastructure Management, National Research Institute for Earth Science and Disaster Prevention, Japan Highway Public Corporation, East Japan Railway Company, Niigata prefecture or Horinouchi Gas Public Company. Domains colored with light gray represent mountain areas and hill areas.

damage (D1) and foundation damage (FD). We classified a structure into D3 if it has been fallen over, or titled more than $1 / 100$, or most of walls or columns have been destroyed and was considered to be un-repairable. We classified a structure into D2 if some structural members have been destroyed and was considered to be repairable. If some structural members have been slightly, if any, damaged, we classified it into D1. If a structure has been obviously damaged by deformation of its foundation, we classified it into foundation damage (FD).
We mapped almost all the houses and barns with their damage classes and main usages (dwelling house or barn). Most of them were wooden structures and the others were reinforced concrete structures or steel structures. We included all type of structure. Component ratios of nonwooden houses in all the worst-hit colonies are several percent except for in Kawaguchi colony. Component ratio of wooden structure types does not differ very much among subregions in each worst-hit colony.

\subsection{Landform classification}




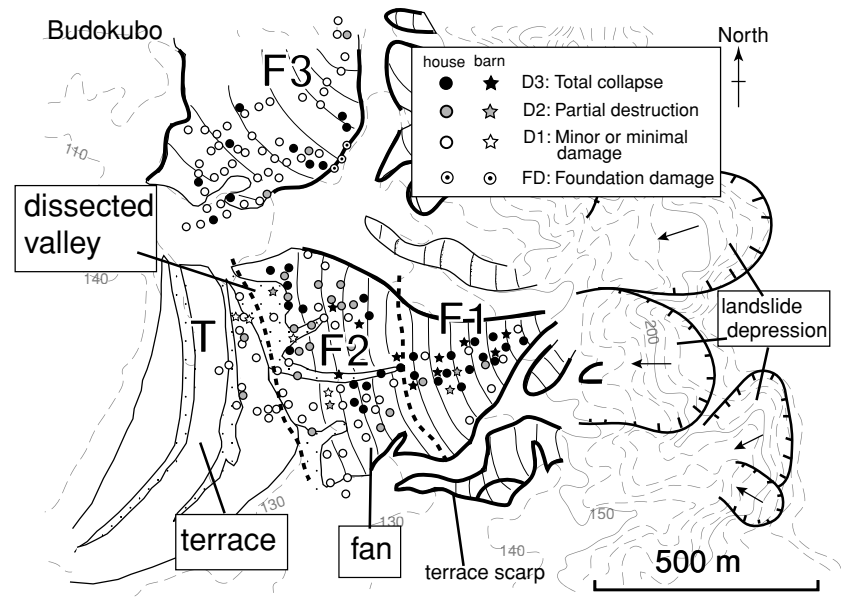

Fig. 2. Landform and damage distribution in Budokubo area. Each house and barn is respectively mapped with circle and star with colors showing damage degree; black: total collapse, dark gray: partial destruction and white: minor or minimal damage, respectively. Bull's eye shows a structure damaged by slumping or slanting of foundation. Buildings on the fan, especially on subregion F1, were more likely suffered severer damage than those on the terrace and dissected valleys. Contour data (10 $\mathrm{m}$ interval) in light gray are from the 1:25000 topographic map "Ojiya", and partly from the 1:10000 topographic map published by Kawaguchi town.

We carried out landform classification on the worst-hit colonies by interpretation of aerial photograph and field survey. Aerial photographs taken by the US Air Force in 1947 were used to classify landforms less affected by artificial alterations. We paid much attention to landforms such as terrace, fan and dissected valley because those landforms were considered to correlate with the severity of damage.

\section{Results and Discussion}

\subsection{Budokubo colony}

Budokubo colony is located on an old meander channel of Shinano River, surrounded by hills consisting of Pliocene mudstone and sandstone with well-developed landslide topographies. A landform classification map of this area is shown in Fig. 2. Main landforms are terrace, fan, dissected valley and terrace scarp. The terrace consists of fluvial gravels 5 to $40 \mathrm{~cm}$ in diameter. On the other hand, the fans are composed of unconsolidated colluvial deposits supplied from the surrounding hills. Fan deposits are about $10 \mathrm{~m}$ thick. The lower part of the deposits includes the $26 \mathrm{ka}$ Aira-Tn tephra, implying that the fans were formed during or after the last glacial stage.

From the topographical point of view, the southern fan can be separated into the steeper upper part (F1) and the gentler lower part (F2). The slope of the upper and lower parts of the fan is about $7 / 100$ and $3 / 100$ on the average, respectively.

We found that 37 houses and 10 barns, among 150 houses and 18 barns, have suffered total collapse. Damage distribution is shown in Fig. 2 and component ratios of damage classes of houses are listed in Table 1. It is implied that the severity of damage has been affected by landforms. Houses on the fan, especially on its upper part, tended to suffer severer damage than those on the terrace, where no total col-
Table 1. Component ratios of damage classes of houses on Budokubo.

\begin{tabular}{l|cccc}
\hline & D3 & D2 & D1 & FD \\
\hline Upper fan: F1 $(n=21)$ & $62 \%$ & $9 \%$ & $29 \%$ & $0 \%$ \\
Lower fan: F2 $(n=57)$ & $25 \%$ & $28 \%$ & $47 \%$ & $0 \%$ \\
Fan: F3 $(n=51)$ & $18 \%$ & $6 \%$ & $71 \%$ & $6 \%$ \\
Terrace: T $(n=15)$ & $0 \%$ & $13 \%$ & $87 \%$ & $0 \%$ \\
\hline All $(n=150)$ & $25 \%$ & $15 \%$ & $58 \%$ & $2 \%$
\end{tabular}

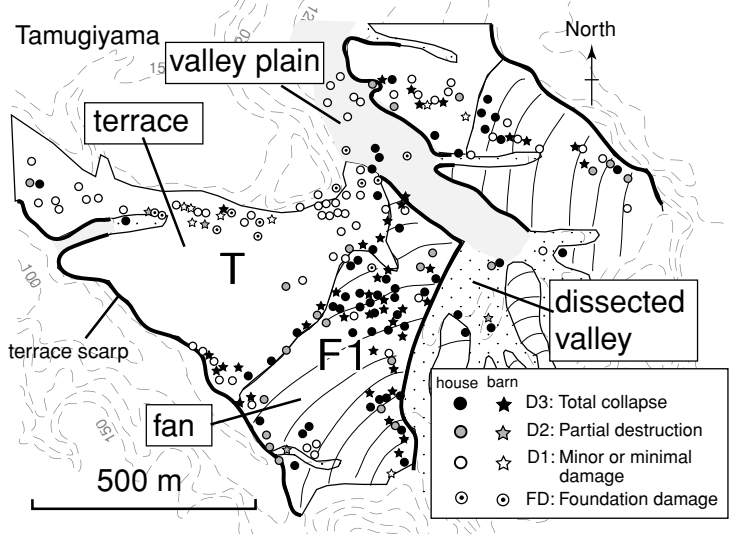

Fig. 3. Landform classification and damage distribution in the Tamugiyama area, likewise as Fig. 2. Buildings on fans were more likely suffered severer damage than those on terraces. F1 is the subregion where the severest damage was observed. Contour data $(10 \mathrm{~m}$ interval) in light gray are from the 1:25000 topographic map "Iwasawa".

lapse (D3) has been observed. This suggests that the ground motion on the fan, especially on its upper part, has been greater than that on the terrace.

\subsection{Tamugiyama colony}

Tamugiyama colony is located on an old meander channel of Uono River, a branch of Shinano River, surrounded by hills composed of Pliocene or Pleistocene sandstone with well-developed landslide topographies. Terrace, fan, dissected valley, valley plain and terrace scarp represent landform of this area as shown in Fig. 3. The terrace deposits mainly consist of gravels interbedded with silt beds, sand and mud. The gravel beds contain pebbles and cobbles of chert and metamorphic rocks derived from the upper reaches of the Uono River. The silt beds intercalate the Aira-Tn tephra. The fans consist of unconsolidated colluvial deposits containing an intercalated Aira-Tn tephra layer. Each fan surface curves convexly and slopes more steeply in the lower part. The terrace is almost flat, gently sloping down to dissected valleys.

We found that 55 houses and 42 barns, among 152 houses (including some stores) and 54 barns, have suffered total collapse. Damage distribution is shown in Fig. 3 and component ratios of damage classes of houses are listed in Table 2. It is shown that damage degree was sensitive to landforms. Houses on the fans tended to suffer severer damage with total collapse (D3) ratio of 59\%, than those on the terraces with total collapse ratio of $16 \%$. Above all, severest damage was observed on the steeply sloping subregion of 
Table 2. Component ratios of damage classes of houses on Tamugiyama.

\begin{tabular}{l|cccc}
\hline & D3 & D2 & D1 & FD \\
\hline Fan $(n=66)$ & $59 \%$ & $17 \%$ & $24 \%$ & $2 \%$ \\
Terrace $(n=69)$ & $16 \%$ & $10 \%$ & $61 \%$ & $13 \%$ \\
Valley $(n=17)$ & $35 \%$ & $12 \%$ & $41 \%$ & $12 \%$ \\
\hline All $(n=152)$ & $36 \%$ & $13 \%$ & $43 \%$ & $8 \%$
\end{tabular}

Table 3. Component ratios of damage classes of houses on Wanazu.

\begin{tabular}{l|cccc}
\hline & D3 & D2 & D1 & FD \\
\hline Fan $(n=63)$ & $37 \%$ & $19 \%$ & $44 \%$ & $0 \%$ \\
Terrace $(n=41)$ & $15 \%$ & $10 \%$ & $76 \%$ & $0 \%$ \\
Valley $(n=26)$ & $27 \%$ & $4 \%$ & $58 \%$ & $12 \%$ \\
\hline All $(n=130)$ & $27 \%$ & $13 \%$ & $58 \%$ & $2 \%$
\end{tabular}

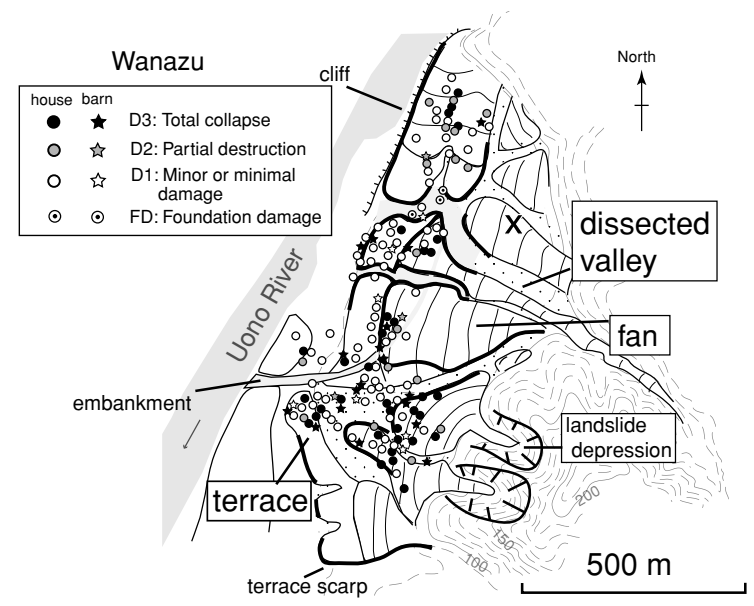

Fig. 4. Landform classification and damage distribution in Wanazu area, likewise as Fig. 2. Buildings on the fans tended to be damaged heavier than those on the terraces. Capital $\mathrm{X}$ denotes the location where ground motion with PGV $152 \mathrm{~cm} / \mathrm{s}$ was observed by East Japan Railway company. Contour data $(10 \mathrm{~m}$ interval) in light gray are from the 1:25000 topographic map "Obiroo".

the southern fan (F1 in Fig. 3). This suggests that the amplification of ground motion on the fans, especially on the subregion with steeper slope, has been greater than that on the terrace.

\subsection{Wanazu colony}

Wanazu colony is located nearby the narrowest point of Uono River and surrounded by hills composed of Pliocene or Pleistocene sandstone with well-developed landslide topographies. Terrace, dissected valley and fan characterize landform of this area as shown in Fig. 4. The terraces are covered with the fans. From the topographycal point of view, the fans and the terraces are inferred to be composed of colluvial deposits supplied from surrounding hills and fluvial deposits, respectively. Ground motion with PGV $152 \mathrm{~cm} / \mathrm{s}$ was observed at the location denoted with capital $\mathrm{X}$ in Fig. 4.

We found that 35 houses and 18 barns, among 130 houses and 28 barns, have suffered total collapse. Damage distribution is shown in Fig. 4 and component ratios of damage
Table 4. Component ratios of damage classes of houses on Shindojima.

\begin{tabular}{l|cccc}
\hline & D3 & D2 & D1 & FD \\
\hline Valley $(n=4)$ & $50 \%$ & $25 \%$ & $25 \%$ & $0 \%$ \\
Fan $(n=38)$ & $42 \%$ & $13 \%$ & $37 \%$ & $8 \%$ \\
Terrace $(n=16)$ & $19 \%$ & $6 \%$ & $75 \%$ & $0 \%$ \\
\hline All $(n=58)$ & $36 \%$ & $12 \%$ & $47 \%$ & $5 \%$
\end{tabular}

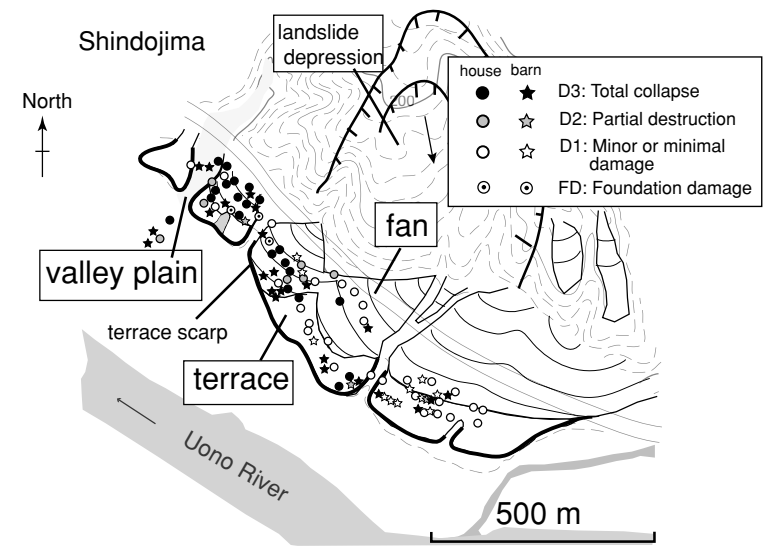

Fig. 5. Landform classification and damage distribution in Shindojima area, likewise as Fig. 2. Buildings on the western subregion were more likely suffered severer damage than those on the eastern subregion. Contour data (10 m interval) in light gray are from the 1:25000 topographic map "Obiroo".

classes of houses are listed in Table 3. Damage distribution in this area shows complicated manner in contrast with that in Tamugiyama or Budokubo. Comparison of the component ratios implies that the severity of damage has been affected by landforms. Houses on the fans tended to be damaged heavier than those on the terraces. This suggests that the ground motions on the fans have been more amplified than those on the terraces.

\subsection{Shindojima colony}

Shindojima colony is located on the foot of a hill covered with Pliocene or Pleistocene sandstone and faces to Uono River. Landslide topographies are well developed on the hill. Terrace, fan and dissected valley represent landform of this area as shown in Fig. 5. The terraces are overlaid by the fans. The fans are inferred to be composed of colluvial deposits supplied from the hill on the back. The fan surface slopes steeper in the western part and gentler in the eastern part.

We found that 21 houses and 21 barns, among 58 houses and 35 barns, have suffered total collapse. Damage distribution is shown in Fig. 5 and component ratios of damage classes of houses are listed in Table 4. The total collapse ratios of houses on the fans and on the terraces are $42 \%$ and $19 \%$, respectively. In addition, totally collapsed houses were tended to concentrate on the steeply sloping western part of the fan. These indicate that the ground motions on the fans, especially on the steeper western part, were greater than those on the terraces.

\subsection{Muikaichi and Nakagata colonies}

Muikaichi and Nakagata colonies are located on fans de- 
Table 5. Component ratios of damage classes of houses on Muikaichi and Nakagata.

\begin{tabular}{l|cccc}
\hline & D3 & D2 & D1 & FD \\
\hline Plain $(n=21)$ & $10 \%$ & $10 \%$ & $81 \%$ & $0 \%$ \\
Valley $(n=6)$ & $83 \%$ & $0 \%$ & $17 \%$ & $0 \%$ \\
fan: F1 $(n=43)$ & $7 \%$ & $30 \%$ & $63 \%$ & $0 \%$ \\
fan: F2 $(n=33)$ & $49 \%$ & $12 \%$ & $39 \%$ & $0 \%$ \\
fan: F3 $(n=74)$ & $10 \%$ & $16 \%$ & $72 \%$ & $3 \%$ \\
\hline All $(n=177)$ & $19 \%$ & $18 \%$ & $64 \%$ & $1 \%$
\end{tabular}

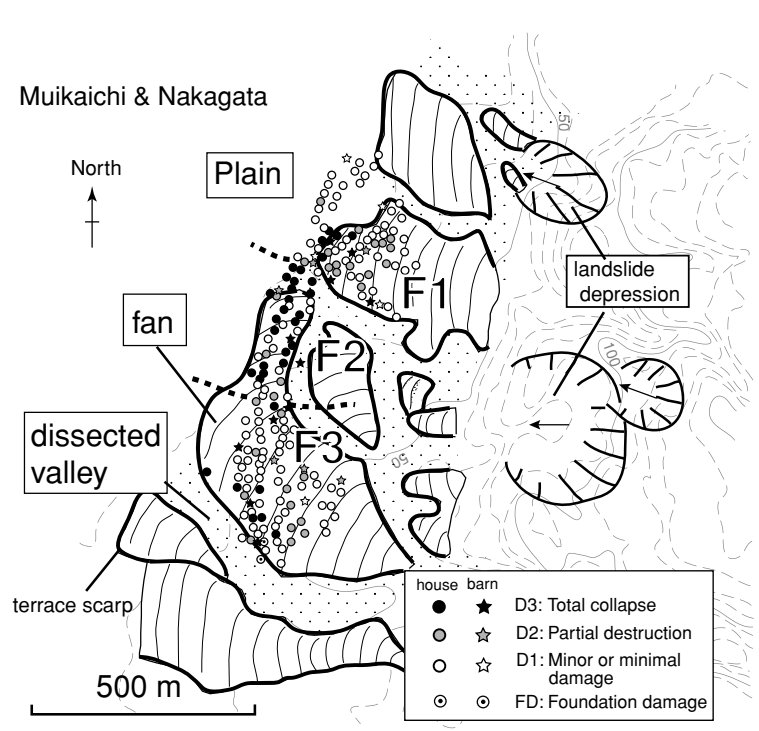

Fig. 6. Landform classification and damage distribution in Muikaichi-Nakagata area, likewise as Fig. 2. Buildings on subregion F2 were more likely suffered severer damage than those on the plain, and subregions F1 and F3. Contour data (10 m interval) in light gray are from the 1:25000 topographic map "Katagai".

veloped on the right bank of Shinano River. Hills with welldeveloped landslide topographies composed of Pliocene or Pleistocene sandstone lie in the east. Fan, dissected valley and alluvial plain represent landform of this area as shown in Fig. 6. The fans in this area can be separated into three subregions: the northern fan (F1), the northern part of the main fan which is about $100 \mathrm{~m}$ wide $(\mathrm{F} 2)$, and the southern part of the main fan (F3). The scarp at the southern edge of F3 is $5 \mathrm{~m}$ high. The scarp at the northwestern edge of F1 is about $2 \mathrm{~m}$ high.

We found that 33 houses and 10 barns, among 177 houses and 22 barns, have suffered total collapse. Damage distribution is shown in Fig. 6 and component ratios of damage classes of houses are listed in Table 5. Total collapse ratio is the highest on subregion F2. It is noteworthy that ratio of total collapse on subregion F2 is about five times higher than those on the other subregions on the fans. This implies that ground motion was much amplified on F2. As subregion F2 is narrow and the others are not, this narrow shape might have caused local amplification.

\subsection{Kawaguchi colony}

Kawaguchi colony is located on a flood plain of Uono River surrounded by a hill with well-developed landslide topographies. Several Holocene old channels are recognized
Table 6. Component ratios of damage classes of houses on Kawaguchi.

\begin{tabular}{l|cccc}
\hline & D3 & D2 & D1 & FD \\
\hline Fan $(n=12)$ & $0 \%$ & $8 \%$ & $8 \%$ & $83 \%$ \\
Plain $(n=273)$ & $22 \%$ & $11 \%$ & $65 \%$ & $2 \%$ \\
Hillside $(n=19)$ & $0 \%$ & $0 \%$ & $32 \%$ & $68 \%$ \\
\hline All $(n=304)$ & $20 \%$ & $11 \%$ & $63 \%$ & $7 \%$
\end{tabular}

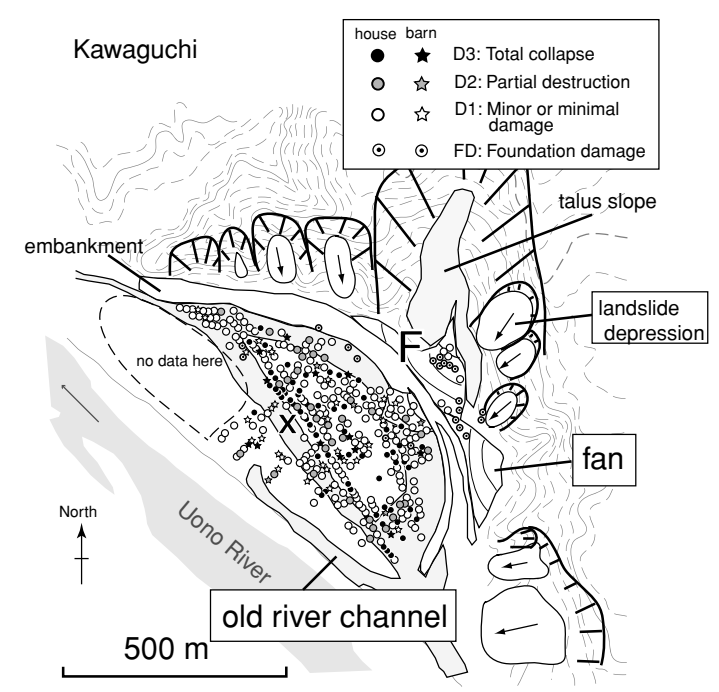

Fig. 7. Landform classification and damage distribution in Kawaguchi area, likewise as Fig. 2. Buildings on hillside F tended to be destroyed by foundation failure. Most of severely damaged buildings on the plain were old. Capital X denotes the location where ground motion with PGV $147 \mathrm{~cm} / \mathrm{s}$ was observed by Niigata Prefecture. Contour data (10 m interval) in light gray are from the 1:25000 topographic map "Ojiya".

in the plain (Fig. 7). The plain slightly slopes down toward the river. An embankment of a railway lies on the border between the hill and the plain. Ground motion with PGV $147 \mathrm{~cm} / \mathrm{s}$ was observed at the location denoted with capital $\mathrm{X}$ in Fig. 7.

We checked 285 houses and stores and 46 barns on the plain excluding northwestern subregion, and 19 houses on the hillside. We found that 61 houses and 13 barns on the plain have suffered total collapse and that most of houses on hillside have been destroyed by foundation failure. Most of severely damaged structures on the plain were old, as reported in other investigations (Sakai et al., 2005; Hisada, 2005). Damage distribution is shown in Fig. 7 and component ratios of damage classes of houses are listed in Table 6.

Severely damaged houses were unevenly distributed in the plain. This unevenness was considered to be related to the distribution of aging houses. We, here, conclude that there have been no clear differences in damage degree between landforms in the plain.

Since the damage was significant in this colony compared to those of other colonies nearby, which are located on terraces, the flood plain might have amplified the ground motion. 


\section{Conclusion}

In the present work, landform and damage classification on worst-hit colonies have been conducted and relation between the damage degree of structures and landform has been examined. We found that buildings on fans tended to suffer severer damage than those on terraces or dissected valleys. This implies that, presumably due to the difference in amplification characteristics, ground motions on the fans were greater than those on the other landforms. This has led to consecutive investigations on the dynamic characteristics of those areas, which are not presented in this report. In these investigations, more quantitative analyses including borehole drilling, the seismic velocity logging, the microtremor measurements and numerical simulations are intended. Nonetheless, it is notable that the differences of damage degree among landforms have been clarified.

Acknowledgments. The quick survey was conducted by $\mathrm{M}$. Yoshimi, K. Yoshida, T. Komatsubara, Y. Miyachi, K. Kimura, S. Kunimatsu and H. Saomoto. The detailed survey on damage was conducted by M. Yoshimi, H. Sekiguchi, M. Saeki and partly by Y. Miyachi, K. Kimura and S. Kunimatsu. Landform classification was conducted by T. Komatsubara, Y. Miyachi, M. Ozaki, T. Nakazawa and R. Nakashima. The authors express their gratitude to Dr. Tom Holzer and Prof. Kazuo Konagai for their helpful sug- gestions on this article. Some parts of figure 1 were plotted with Generic Mapping Tools (GMT) by Wessel and Smith (1998).

\section{References}

Geographical Survey Institute Japan, Results from urgent leveling measurements after the 2004 mid-Niigata prefecture, Japan, earthquake, http://www.gsi.go.jp/WNEW/PRESS-RELEASE/2004/1227.htm, 2004 (in Japanese).

Hisada, Y., 2004 Niigata-ken Chuetsu Earthquake Sub-Surface Soil Condition and Earthquake Damage, Proceedings of the 32nd Symposium of Earthquake Ground Motion, Architectural Institute of Japan, 21-31, 2005 (in Japanese).

Japan Meteorological Agency, The seismological and volcanological bulletin of the Japan Meteorological Agency for October 2004, 2004.

Niigata Prefecture, Damage report of the 2004 Niigata-ken Chuetsu earthquake, http://saigai.pref.niigata.jp/content/jishin/higai_125.html, 2005 (in Japanese).

Sakai, Y., S. Kosugi, T. Ohtsuki, and Y. Nakamura, Strong motions and damage of structures, Proceedings of the Symposium on the 2004 Niigata-ken Chuetsu earthquake, Japan Association for Earthquake Engineering, 27-34, 2005 (in Japanese).

Wessel, P. and W. H. F. Smith, New, improved version of Generic Mapping Tools released, EOS, 79, 579, 1998.

M. Yoshimi (e-mail: yoshimi.m@aist.go.jp), T. Komatsubara, Y. Miyachi, K. Kimura, H. Sekiguchi, M. Saeki, S. Kunimatsu, K. Yoshida, M. Ozaki, T. Nakazawa, R. Nakashima, and H. Saomoto 